\title{
Development of a rapid method for the measurement of lactose in milk using a blood glucose biosensor
}

\author{
J. K. Amamcharla and L. E. Metzger ${ }^{1}$ \\ Midwest Dairy Foods Research Center, Dairy Science Department, South Dakota State University, Brookings 57007-0647
}

\begin{abstract}
Current methods for lactose measurement in dairy products are time consuming and tedious and may require expensive equipment and skilled technicians. The aim of this research was to develop a novel and rapid method for the routine measurement of lactose in dairy products. The proposed method is based on the rapid hydrolysis of lactose using $\beta$-galactosidase and subsequently measuring glucose using a blood glucose meter. Blood glucose meters were developed after decades of research and clinical trials and are used extensively worldwide by individuals with diabetes to monitor their blood glucose levels. The method was developed and validated in a series of experiments. In the first experiment, temperature and time required for the near-complete hydrolysis of lactose were determined. Subsequently, the influence of glucose meters and their test strip lots were evaluated. We found that meters were not significantly different. However, the test strip lots were significantly different from each other. In the second experiment, the proposed method was validated using different concentrations of lactose solutions (1.9-6.5\%) and compared with a HPLC-based reference method. In the third experiment, the proposed method was used to determine the lactose content of raw milk. The proposed method shows potential for rapid, routine, and low-cost measurement of lactose in milk and other dairy products.
\end{abstract}

Key words: rapid method, lactose, blood glucose meter, milk

\section{INTRODUCTION}

Lactose is the primary carbohydrate present in the milk of most mammals. The lactose content of normal cow milk is generally between 4.4 and 5.2\% (Morrissey, 1985). Lactose is also important for its economic value and contributions to the sensory and functional properties of dairy products (Lynch et al., 2007). Rapid and

Received April 4, 2011.

Accepted June 21, 2011.

${ }^{1}$ Corresponding author: Lloyd.Metzger@sdstate.edu accurate determination of lactose is critical in process control of cheese whey fermentation (Jeon et al., 1984; Abboud et al., 2010) as well as in membrane separation of lactose from cheese whey (Cuartas-Uribe et al., 2009). Consequently, the availability of a rapid and inexpensive method for lactose determination has ramifications for the dairy industry (Iwasaki et al., 2008).

Several methods are available to determine the lactose content of milk and milk products, including HPLC (West and Llorente, 1981; Kwak and Jeon, 1988; Upreti et al., 2006), an enzymatic method (Essig and Kleyn, 1983; Kleyn, 1985; Lynch et al., 2007), polarimetry (method 896.01; AOAC, 2000), and a gravimetric method (method 930.28; AOAC, 2000). The enzymaticbased method has several advantages over the other methods in terms of availability of test reagents in the form of a kit and an optimized procedure for milk and other dairy products. In a collaborative study conducted by Kleyn and Trout (1984), the enzymatic method was compared with the AOAC gravimetric method. They found that the lactose content using the enzymatic method was $0.49 \%$ lower than the gravimetric method (overall mean comparison) and concluded a lack of agreement between the 2 methods. In contrast to this, Essig and Kleyn (1983) compared the enzymatic method with the AOAC copper reduction method (930.28; AOAC, 2000) and found good agreement between the 2 methods. Lynch et al. (2007) recommended path length adjustments and weight measurement for the enzymatic method and considerably improved the performance of the method. The repeatability relative standard deviation $\left(\mathrm{RSD}_{\mathrm{r}}\right)$ and the reproducibility relative standard deviation $\left(\mathrm{RSD}_{\mathrm{R}}\right)$ for the improved method calculated from the results of 11 laboratories and 8 pairs of blind replicates were found to be 0.29 and $0.57 \%$, respectively.

In addition to these methods, lactose-by-difference is a popular shortcut method for indirect estimation of lactose in dairy products such as milk, cheese, and whey. However, the measurement errors in determination of total solids, protein, fat, and minerals are combined and result in a high degree of uncertainty in lactose estimation (Lynch et al., 2007). Moreover, compounds such as organic acids and other trace com- 
pounds are miscalculated as lactose. Several researchers have proposed different biosensors (Lukacheva et al., 2007; Marrakchi et al., 2008; Conzuelo et al., 2010) for the measurement of lactose in liquid samples. Most of the biosensors are based on amperometric or conductometric sensing techniques and require additional research to be applied as a routine method for lactose determination in a dairy plant environment.

Currently available methods for determination of lactose have limitations, including time requirements and the need for expensive instrumentation, and skilled technicians. Consequently, the dairy industry is in need of a rapid and inexpensive method that can be performed with minimal training of the analyst. To meet these requirements, a cost-effective approach is to adapt an existing technology and use it for the determination of lactose in milk and milk products. In this regard, a novel method utilizing a commercially available blood glucose biosensor is proposed.

Blood glucose meters were developed after decades of extensive research and clinical trials. They are used worldwide to monitor blood glucose concentration. The technology of glucose meters and their clinical and technological evaluations can be found in various publications (Bergenstal et al., 2000; Briggs and Cornell, 2004; Kimberly et al., 2006; Hones et al., 2008). Blood glucose meters are extremely user-friendly and require a very small sample size. The first step in utilizing a blood glucose meter for the measurement of lactose in dairy products is to hydrolyze the lactose into glucose and galactose using $\beta$-galactosidase. This step is utilized in any method involving the enzymatic determination of lactose. The reaction is as follows: Lactose $+\mathrm{H}_{2} \mathrm{O} \stackrel{\beta \text {-galactosidase }}{\longrightarrow}$ glucose + galactose.

The amount of glucose formed during the hydrolysis of lactose is proportional to the amount of lactose present in the sample. Subsequently, the concentration of glucose is determined using a blood glucose meter. The output from the blood glucose meter is then used to determine the lactose concentration in the sample. The objective of the present study was to develop and evaluate a blood glucose meter-based method for determination of lactose in milk.

\section{MATERIALS AND METHODS}

\section{Experimental Design}

The experimental approach was conducted in 3 experiments. In the first experiment, the ideal conditions for complete hydrolysis of lactose and the effect of blood glucose meters and their test strip lots were studied. In the second experiment, the proposed method was validated by using 25 model lactose solutions using 5 lots of test strips. In the last experiment, the novel blood glucose meter method was evaluated in milk.

\section{Model Solutions}

A lactose model solution was prepared by dissolving lactose monohydrate (Fisher Scientific, Pittsburgh, PA) in distilled water to produce a concentration of $0.38 \%$ $(380 \mathrm{mg} / \mathrm{dL})$ lactose. The $0.38 \%$ lactose solution was diluted with distilled water to produce 8 lactose model solutions $(0.05,0.09,0.14,0.19,0.24,0.29,0.33$, and $0.38 \%$ ). The lactose concentration was later confirmed using a HPLC-based reference method. Fresh lactose model solutions were prepared during the course of this research and analyzed on the same day.

\section{Blood Glucose Meter}

ReliOn Ultima self-monitoring blood glucose meters and their test strips (Wal-Mart, Bentonville, AR) were used to measure the lactose concentration in the model solutions as well as in the milk samples. The meters and their test strips were purchased from a local supermarket. The working range of the glucose meters was between 20 and $500 \mathrm{mg} / \mathrm{dL}(0.02-0.5 \%$, wt/vol). Any measurement below or above this range was displayed on the meter as "LO" or "HI," respectively.

Theoretically, blood glucose meters from any manufacturer can be used to measure the lactose concentration in milk and milk products. However, the most important factor in selecting a blood glucose meter for measurement of lactose is that some blood glucose meters and test strips are influenced by the presence of galactose, maltose, or xylose. Galactose was our primary concern because it is one of the end products in lactose hydrolysis. Blood glucose meters that work on glucose dehydrogenase pyrroloquinoline-quinone (GDH-PQQ) or glucose dye oxidoreductase principles are not specific to glucose and can give an elevated glucose meter reading in the presence of galactose (Schleis, 2007). However, blood glucose meters and test strips that function on glucose dehydrogenase nicotinamide adenine dinucleotide (GDH-NAD), glucose oxidase, or glucose hexokinase are the most suitable for determination of lactose in milk. The ReliOn blood glucose meter used in the present work is based on GDH-NAD and is not influenced by galactose. Schleis (2007) provided a list of glucose monitoring systems along with the enzyme utilized in each of the systems.

\section{Enzyme}

$\beta$-Galactosidase, commonly called lactase, was obtained from Enzyme Development Corp. (New York, 
NY). The enzyme had an activity of 2,300 to 2,700 yeast lactase units/g. It is derived from the dairy yeast Kluveromyces and has optimum activity between 31 and $40^{\circ} \mathrm{C}$.

\section{HPLC-Based Reference Method}

A HPLC system (Beckman Coulter Inc., Fullerton, CA) equipped with a solvent delivery module (System Gold 125), a multichannel wavelength scanning detector (190-600 nm; System Gold 168 detector), and a $20-\mu$ L sample injection loop (Rheodyne, Rohnert Park, $\mathrm{CA}$ ) was used to measure the lactose concentration of model solutions and milk. The HPLC system also included a refractive index detector (RI-2031, Jasco Corporation, Hachioji, Japan) and a model 631 column heater (Alltech, Deerfield, IL). A 300- × 7.80-mm ion exclusion column (ROA-Organic Acid, Phenomenex Inc., Torrance, CA) maintained at $65^{\circ} \mathrm{C}$ was used for separation of lactose. Sulfuric acid $(0.013 N)$ was used as mobile phase at a flow rate of $0.6 \mathrm{~mL} / \mathrm{min}$. The mobile phase was prepared by dissolving sulfuric acid (Sigma-Aldrich, St. Louis, MO) in HPLC-grade water (Fisher Scientific, Pittsburgh, PA).

Sample Preparation of Lactose Model Solutions. Model solutions of lactose were filtered through $0.45-\mu \mathrm{m}$ polyvinylidene fluoride syringe filter and directly injected into the injection loop of the HPLC system. Lactose was quantified using an external standard method as described by Upreti et al. (2006) and was measured using the refractive index detector only.

Sample Preparation of Milk. Approximately 0.5 $\mathrm{mL}$ of the diluted milk ( $1 \mathrm{~g}$ of milk mixed with $20 \mathrm{~g}$ of distilled water) was poured into a Microcon centrifugal filter (Millipore Corp., Bedford, MA) with a molecular weight cutoff of $3 \mathrm{kDa}$. The tubes were centrifuged (Jouan Inc., Winchester, VA) at 17,746 $\times g$ for $15 \mathrm{~min}$. The collected filtrate was vortexed and injected into the HPLC system. Lactose was quantified in milk samples based on the external standard method as described by Upreti et al. (2006).

\section{Experiment 1}

In experiment 1, efforts were focused on reducing the time required for complete hydrolysis of lactose as well as studying the factors that influence the output of the blood glucose meter. Initially, an experiment was conducted to optimize the conditions required for complete hydrolysis of lactose. For this purpose, a $0.35 \%$ lactose solution, which was close to the highest lactose content model solution, was selected. We assumed that the optimum conditions for complete hydrolysis for $0.35 \%$ lactose could be applied to the lower lactose concentra- tions. A series of glass test tubes containing $5 \mathrm{~mL}$ of $0.35 \%$ lactose solution and $0.1 \mathrm{~mL}$ of $\beta$-galactosidase were incubated at 4 selected temperatures $(20,25,30$, and $40^{\circ} \mathrm{C}$ ) in a water bath [Grant Instruments (Cambridge) Ltd., Barrington, UK]. The test tubes containing the lactose solutions were removed from the water bath at specified intervals $(0,1,2,3,5,7,9,12$, and $15 \mathrm{~min}$ ) and placed in a boiling water bath for $5 \mathrm{~min}$ to inactivate the enzyme. Extreme care was taken to prevent moisture loss during the enzyme inactivation process. The hydrolyzed lactose solution was then cooled to room temperature and analyzed for lactose using the previously described HPLC-based method.

Subsequently, an experiment was conducted to evaluate the effects of blood glucose meter, test strip lot, and concentration of lactose in models solutions on the blood glucose meter output. For this purpose, we used a randomized factorial design with 3 factors (glucose meters 1 and 2; test strip lots 1 and 2; and 8 model solutions with lactose concentrations ranging from 0.05 to $0.38 \%$ ). For this purpose, $5 \mathrm{~mL}$ of lactose solution and $0.1 \mathrm{~mL}$ of lactase enzyme were vortexed and incubated at $40^{\circ} \mathrm{C}$. After $10 \mathrm{~min}$, the sample was analyzed with 2 glucose meters using 2 lots of test strips. In each test strip lot, triplicate measurements were recorded. The blood glucose meter readings were tabulated and analyzed using the PROC GLM procedure in SAS (version 9.1, SAS Institute Inc., Cary, NC).

\section{Experiment 2}

The goal of experiment 2 was to validate the proposed method in model solutions. To conduct this experiment, 1 glucose meter and 5 lots of test strips were used. Initially, calibration curves were derived from the blood glucose meter responses of each lot of test strips using 8 standard lactose model solutions ranging from 0.05 to $0.38 \%(0.05,0.09,0.14,0.19,0.24,0.29,0.33$, and $0.38 \%$ ). Each standard solution was analyzed in duplicate to record the blood glucose meter reading. Simultaneously, the standard solutions were analyzed for lactose concentration using the HPLC-based reference method. A universal calibration model was also developed by pooling the data from all of the test strip lots to develop a single regression model. Additionally, the readings from each lot of test strips and their corresponding lactose concentrations from the HPLC-based reference method were individually analyzed to develop a lot-specific calibration equation for each lot of test strips. Subsequently, 25 new model lactose solutions that ranged in concentration from 1.9 to $6.5 \%$ lactose were prepared independently (by dissolving lactose in distilled water) and measured for lactose concentration using the proposed blood glucose meter method. The 
concentration of lactose using both the lot-specific calibration equations and the calibration equation from the pooled data was determined.

The lactose concentrations obtained from each lot of test strips using the blood glucose meter method and the HPLC-based reference method were tabulated and compared using method comparison statistics including regression analysis. Microsoft Excel (Microsoft Corp., Seattle, WA) was used to develop linear regression models. From the regression analysis, statistical parameters such as slope, intercept, their $95 \%$ confidence intervals, and standard deviation of residuals were extracted. In addition, paired $t$-test was conducted to evaluate the agreement between the reference method and the proposed method. Other indices such as mean difference (d) and mean percentage difference $(\mathbf{D})$ were also used to evaluate the proposed method performance.

\section{Experiment 3}

In experiment 3 , calibration equations were developed using a model skim milk solution and the method was validated using 10 raw milk samples. Model skim milks were prepared that contained $3.5 \%$ protein and varying concentrations of lactose (targeted at 2, 3, 4, 5, and 6\%) using milk protein concentrate 85 (DairiConcepts, Springfield, MO), deproteinized whey powder (VersiLac, Proliant Dairy Ingredients, Ankeny, IA), and distilled water. The calibration samples were then analyzed for actual lactose content using the previously described HPLC-based reference method. For the blood glucose meter method, approximately $1 \mathrm{~g}$ of model skim milk was diluted with $20 \mathrm{~g}$ of distilled water. A portion of the diluted sample $(5 \mathrm{~mL})$ was mixed with $0.1 \mathrm{~mL}$ of $\beta$-galactosidase and incubated at $40^{\circ} \mathrm{C}$ for $10 \mathrm{~min}$. Two test strip lots (duplicate measurements within each lot) were used to evaluate each sample, and lot-specific and universal (by pooling the data from both the strip lots) calibration curves were developed.

Ten raw milk samples were obtained from individual cows at the Dairy Research and Training Facility (Dairy Science Department, South Dakota State University, Brookings). Each sample was analyzed for lactose content using the blood glucose meter method and the HPLC-based reference method. In the proposed blood glucose meter method, $1 \mathrm{~g}$ of milk was diluted with $20 \mathrm{~g}$ of distilled water and vortexed. Then, $0.1 \mathrm{~mL}$ of $\beta$-galactosidase was added to $5 \mathrm{~mL}$ of diluted milk sample and incubated at $40^{\circ} \mathrm{C}$ in a water bath. After $10 \mathrm{~min}$, the diluted milk sample was vortexed and analyzed in duplicate using a blood glucose meter. Lactose concentration was calculated from the blood glucose meter reading using universal and lot-specific calibration models. The lactose contents obtained using the blood glucose meter and reference methods were compared.

The lactose concentrations obtained from each lot of test strips using the blood glucose meter method were compared with the HPLC-based reference method using method comparison statistics including regression analysis. Excel (Microsoft Corp.) was used to develop linear regression models. Statistical parameters such as slope, intercept, their $95 \%$ confidence intervals, and standard deviation of residuals were extracted from linear regression analysis. In addition, a paired $t$-test was conducted to evaluate the agreement between the 2 methods. Additionally, other indices such as $\mathrm{d}$ and D were used to evaluate the proposed method performance.

\section{RESULTS AND DISCUSSION}

\section{Experiment 1}

Hydrolysis of Lactose. Lactose hydrolysis using $\beta$-galactosidase was the first step in the proposed blood glucose meter method. Figure 1 illustrates the gradual reduction of lactose during incubation with $\beta$-galactosidase. Lactose was not detected in the HPLCbased method after 15, 10, 8, and 6 min of incubation at $20,25,30$, and $40^{\circ} \mathrm{C}$, respectively. Consequently, lactose was completely hydrolyzed within $10 \mathrm{~min}$ when the incubation temperature was between 25 and $40^{\circ} \mathrm{C}$. Kosinski (1981) reported that the rate of hydrolysis of lactose was dependent on the temperature. In the remainder of our research, hydrolysis conditions were standardized at $2 \%$ enzyme addition with incubation at $40^{\circ} \mathrm{C}$ for a minimum of $10 \mathrm{~min}$.

Effect of Glucose Meter, Test Strip Lot, and Lactose Concentration. As shown in Table 1, blood glucose meter output was significantly $(P<0.05)$ influenced by test strip lot and initial lactose concentration in the model solutions. However, glucose meter and the interaction terms were not significant $(P>0.05)$. Kristensen et al. (2005) studied the between-lot variation in external quality assessment of glucose meters. The authors concluded that the between-lot differences were significant and found as much as a $1.3 \mathrm{mmol} / \mathrm{L}$ $(23.4 \mathrm{mg} / \mathrm{dL})$ difference in control solutions. As shown in Table 2, the average absolute difference between 2 test strip lots was relatively high $(16 \mathrm{mg} / \mathrm{dL})$ at the highest lactose concentration (381 $\mathrm{mg} / \mathrm{dL})$ analyzed. However, for the remaining lactose concentrations (48 to $333 \mathrm{mg} / \mathrm{dL}$ ), the average absolute difference was less than $7.4 \mathrm{mg} / \mathrm{dL}$. Our results show that the variation was less than previously reported values, probably due to advancements in test strip technology since the previous study by Kristensen et al. (2005). 


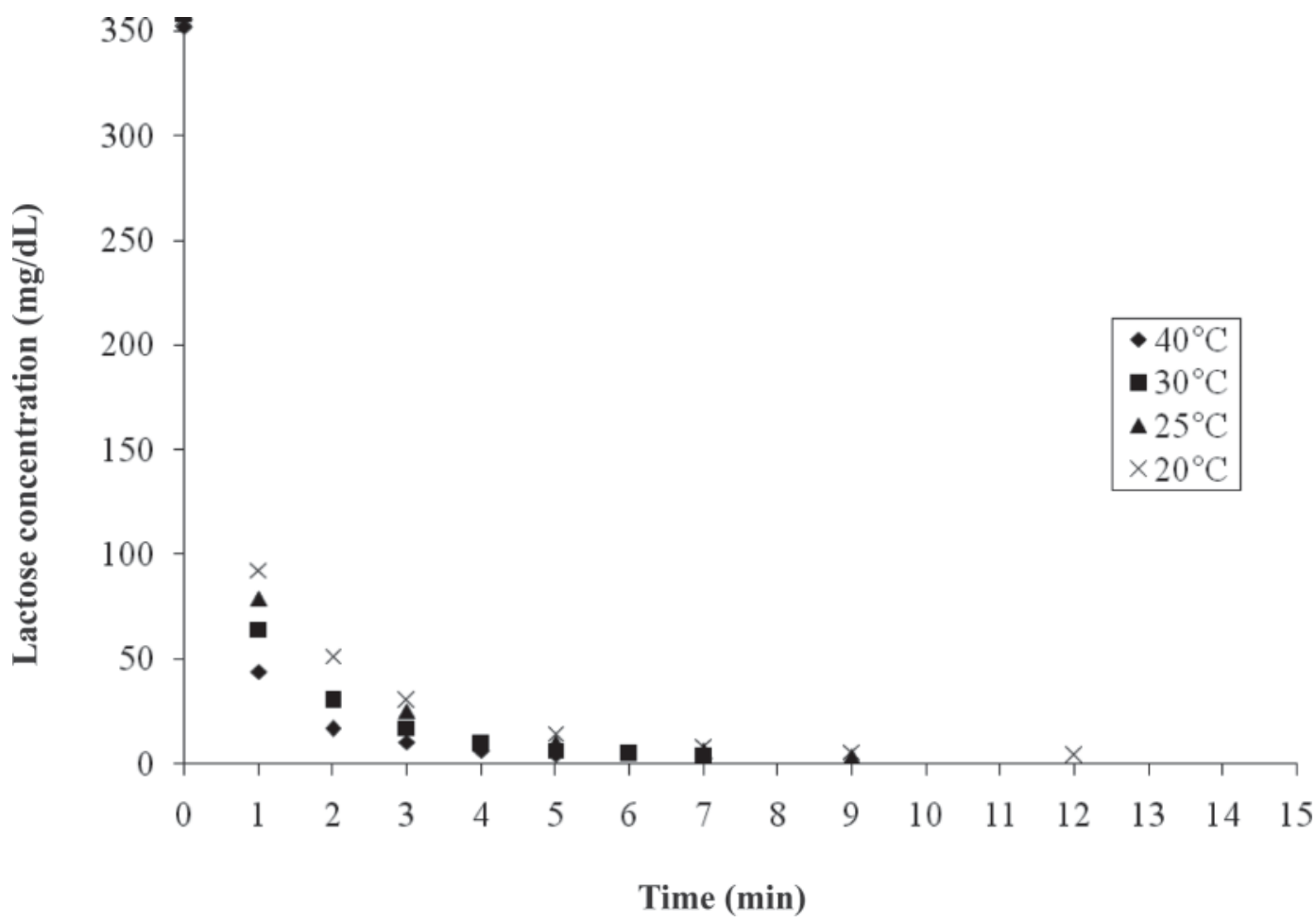

Figure 1. Changes in the remaining lactose content during the hydrolysis of lactose incubated at $20,25,30$, and $40^{\circ} \mathrm{C}$ for different times.

Figure 2 shows the linear relationship between the actual lactose concentration (HPLC-based method) and the corresponding average glucose meter reading. The average glucose meter reading was obtained by averaging all the data points $(2$ meters, 2 strip lots, and 3 replications). Regression analysis yielded a correlation coefficient of 0.999 with a slope of 0.855 and an intercept of -18.77 . Of note is the observation (Table 2 ) that the average glucose meter reading was higher than the theoretical glucose concentration of the model solution, except for the lowest lactose concentration. Hydrolysis of lactose yields equal proportions of glucose and galactose (Holsinger, 1997). The theoretical glucose concentration was calculated as half of the lactose concentration (e.g., a 1\% lactose solution hydrolyzes into a solution containing $0.5 \%$ glucose and $0.5 \%$ galactose). It was also observed that the difference between the theoretical glucose concentration and blood glucose meter reading increased linearly $\left(\mathrm{r}^{2}=0.998\right)$ as the theoretical glucose concentration increased, indicating a proportional error in the glucose measurement. It was also found that the elevated glucose meter reading was not due to interference of galactose. The lack of interference from galactose was confirmed by analyzing

Table 1. Mean squares and probabilities of glucose meter output when exposed to different concentrations of lactose

\begin{tabular}{lccc}
\hline & & \multicolumn{2}{c}{ Glucose meter reading } \\
\cline { 3 - 4 } Source of variation & df & Mean squares & $P>F$ \\
\hline Test strip lot & 1 & $513.5^{*}$ & 0.0086 \\
Meter & 1 & 65.3 & 0.3438 \\
Concentration & 7 & $243,227.0^{*}$ & $<0.0001$ \\
Strip lot $\times$ meter & 1 & 1.7 & 0.8789 \\
Strip lot $\times$ concentration & 7 & 22.9 & 0.946 \\
Concentration $\times$ meter & 7 & 37.3 & 0.8223 \\
Strip lot $\times$ meter $\times$ concentration & 7 & 16.7 & 0.9774 \\
Error & 160 & 72.46 & \\
Total & 191 & & \\
$* P<0.05$ & & &
\end{tabular}


Table 2. Average glucose meter reading obtained, with SD and CV, when exposed to different concentrations of lactose

\begin{tabular}{|c|c|c|c|c|c|c|}
\hline $\begin{array}{l}\text { Lactose } \\
\text { concentration }{ }^{1} \\
(\mathrm{mg} / \mathrm{dL})\end{array}$ & $\begin{array}{l}\text { Theoretical } \\
\text { glucose } \\
\text { concentration } \\
(\mathrm{M} ; \mathrm{mg} / \mathrm{dL})\end{array}$ & $\begin{array}{c}\text { Average } \\
\text { glucose meter } \\
\text { reading } \\
(\mathrm{N} ; \mathrm{mg} / \mathrm{dL})\end{array}$ & $\begin{array}{l}\mathrm{M}-\mathrm{N}^{2} \\
(\mathrm{mg} / \mathrm{dL})\end{array}$ & $\mathrm{SD}$ & $\% \mathrm{CV}$ & $\begin{array}{l}\text { Average absolute } \\
\text { difference } \\
\text { between } 2 \text { lots } \\
(\mathrm{mg} / \mathrm{dL})\end{array}$ \\
\hline 47.7 & 23.9 & 20.3 & 3.6 & 0.4 & 1.9 & 0.1 \\
\hline 95.0 & 47.5 & 62.2 & -14.7 & 2.6 & 4.2 & 3.6 \\
\hline 142.7 & 71.4 & 103.5 & -32.1 & 3.5 & 3.4 & 4.1 \\
\hline 190.4 & 95.2 & 144.4 & -49.2 & 3.4 & 2.3 & 5.0 \\
\hline 236.2 & 118.1 & 185.9 & -67.8 & 5.3 & 2.9 & 7.4 \\
\hline 285.4 & 142.7 & 227.0 & -84.3 & 8.0 & 3.5 & 5.7 \\
\hline 333.1 & 166.6 & 266.6 & -100 & 10.4 & 3.9 & 4.0 \\
\hline 380.7 & 190.4 & 303.7 & -113.3 & 12.1 & 4.0 & 16.1 \\
\hline
\end{tabular}

lactose model solutions containing $0.25 \%$ lactose that were spiked with varying concentrations of galactose $(0$, $0.05,0.1,0.25$, and $0.4 \%$ ). Each solution was analyzed in duplicate and the average glucose meter readings were found to be $163,161.5,161.5,164.0$, and $161.5 \mathrm{mg} / \mathrm{dL}$ for the model solutions containing $0.25 \%$ lactose and 0 , $0.05,0.1,0.25$, or $0.4 \%$ galactose, respectively. Because all samples gave similar results even though they had a wide range of galactose contents, the presence of galactose did not interfere with glucose measurement by the glucose meter.

Table 2 also shows the lactose concentration of the model solutions and the glucose meter digital output along with the standard deviation and CV calculated from the triplicate measurements. The CV was less than $5 \%$ at all concentrations. The lowest concentration had the lowest CV (1.99\%), whereas that at other concentrations ranged from 2.3 to $4.2 \%$. Cohen et al. (2006) presented similar results when they compared the performance of 5 blood glucose meters. However, none of those meters was the model used in the cur-

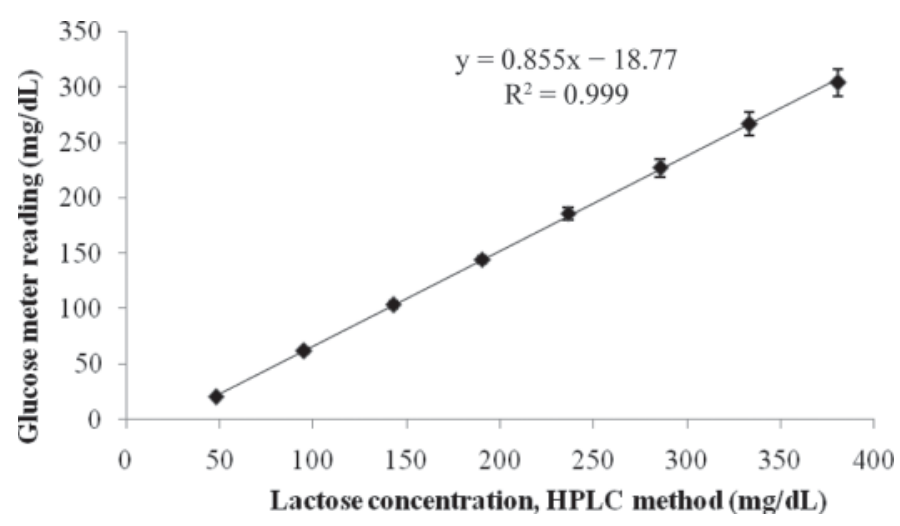

Figure 2. Average response of the blood glucose meter at different concentrations of lactose in model solutions. rent study. Using the control solutions provided by the manufacturer, they reported $\mathrm{CV}$ between 2.8 and $5.5 \%$. They also reported that the variation was less at higher concentrations and greater for lower glucose concentrations in the control solutions. The variability in glucose meter readings could be dependent on the manufacturing conditions of the test strips and the principle behind the blood glucose meters. Because the test strip lot significantly influenced the glucose meter reading, the next logical step was to complete an indepth analysis of the lot-to-lot variability in test strip performance.

\section{Experiment 2}

The lactose contents of 25 independently prepared model lactose solutions that ranged in concentration from 1.9 to $6.5 \%$ were measured using the HPLC-based reference method and the proposed glucose meter method. The method comparison parameters for the universal calibration model and 5 lot-specific calibration models are shown in Tables 3 and 4, respectively.

Universal Calibration Model. The linear regression parameters obtained using the universal calibration model for different test strip lots are provided in Table 3. The slopes and intercepts of the regression lines between the actual lactose content (HPLC-based method) and the lactose content obtained using the glucose meter method ranged from 1.008 to 1.07 and from -0.131 to 0.076 , respectively. None of the intercepts was significantly $(P>0.05)$ different from zero. However, one of the lots (lot 4) produced a slope that was significantly $(P<0.05)$ different from 1 . An intercept and slope that are not significantly different from 0 and 1, respectively, usually indicate agreement between the reference method and the method under development. The standard deviation of the residuals $\left(\mathrm{S}_{\mathrm{y}, \mathrm{x}}\right)$ was between 0.093 and 0.133 for the 5 lots of 
Table 3. Comparison of the proposed method with the HPLC-based method for measurement of lactose in model solutions using different lots of test strips and universal calibration model

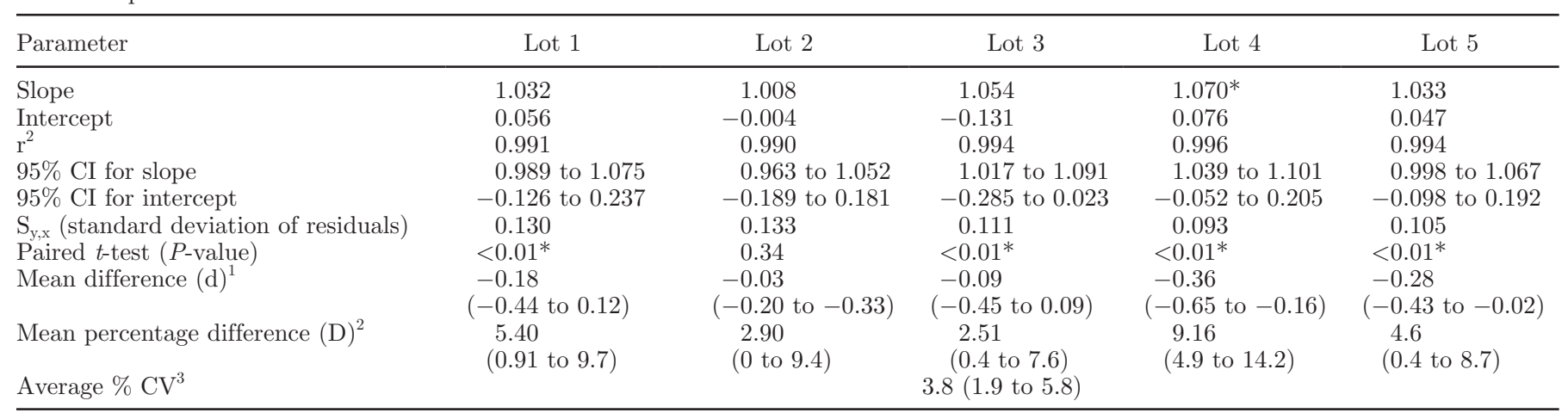

${ }^{1} \mathrm{~d}=\mathrm{A}-\mathrm{B}$, where $\mathrm{A}$ is the HPLC-based method and B is the proposed method (range is shown in parentheses).

${ }_{2} \mathrm{D}(\%)=\frac{|\mathrm{A}-\mathrm{B}|}{\mathrm{A}} \times 100$, where $\mathrm{A}$ is the HPLC-based method and B is the proposed method (range is shown in parentheses).

${ }^{3}$ Calculated between lots 1 to 5 for 25 samples.

$* P<0.05$.

test strips (Table 3). The mean difference between the HPLC method and the proposed method is also shown in Table 3 and it ranged from -0.03 to -0.36 for lots 2 and 4 , respectively. Lots 2 and 3 had a mean difference $<0.1$, whereas the remaining lots produced a relatively high mean difference. We also observed that the mean difference was always less than zero, indicating that the proposed method produced lower values when compared with the HPLC-based method. Mean percentage difference (D) followed a similar trend. The average $\mathrm{CV}$, calculated by considering the 5 lots as replications, was calculated to be $3.8 \%$. The relatively high $\mathrm{CV}$ and lot-to-lot variation in the mean difference between the glucose meter method and HPLC-based method suggest that development of lot-specific calibration equations may be required.
Lot-Specific Calibration Models. Lot-specific calibration models were developed for the 5 test strip lots and then used to calculate the lactose concentration in model solutions. Table 4 provides linear regression parameters obtained using the lot-specific calibration models for the 5 lots of test strips. The regression coefficients were between 0.94 and 1.025. All regression coefficients except for those of lot 3 were not significantly different from 1 . The intercepts of the regression lines were also not significantly different from zero for all 5 lots. Slopes not significantly different from 1 and intercepts not significantly different from zero indicate good agreement between the methods. Using the universal calibration model, lot 4 yielded the highest $\mathrm{d}$ and $\mathrm{D}$ values (Table 3 ). However, d and $\mathrm{D}$ were drastically reduced to 0.02 and $2.19 \%$, respectively, for lot 4 when

Table 4. Comparison of the proposed method with the HPLC-based method for measurement of lactose in model solutions using different lots of test strips and lot-specific calibration model

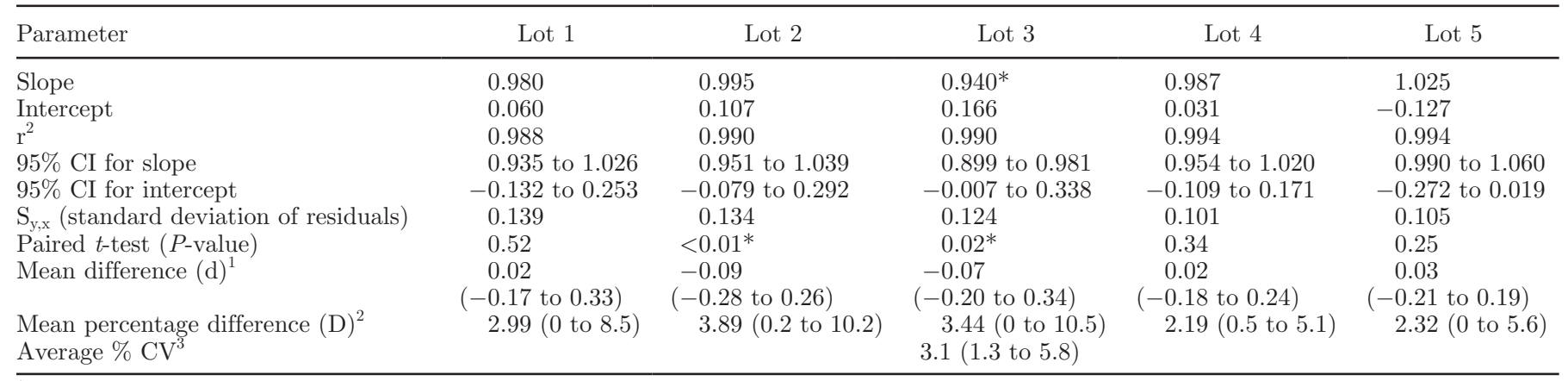

${ }^{1} \mathrm{~d}=\mathrm{A}-\mathrm{B}$, where $\mathrm{A}$ is the HPLC-based method and B is the proposed method (range is shown in parentheses).

${ }_{2} \mathrm{D}(\%)=\frac{|\mathrm{A}-\mathrm{B}|}{\mathrm{A}} \times 100$, where $\mathrm{A}$ is the HPLC-based method and B is the proposed method (range is shown in parentheses).

${ }^{3}$ Calculated between lots 1 to 5 for 25 samples.

$* P<0.05$. 
the lot-specific calibration model was used to predict the lactose concentration. The $\mathrm{D}$ value was always $<4 \%$ for all 5 test strip lots when the lot-specific calibration models were used. From Tables 3 and 4, we concluded that the lot-specific calibration equations provide better predictability of lactose in models solutions compared with the universal calibration equation. The paired $t$ test also yielded a similar interpretation. The results obtained on the model lactose solutions encouraged us to extend the proposed method to milk samples.

\section{Experiment 3: Method Validation on Milk Samples}

The lactose contents in the 5 model skim milk solutions were targeted at $2,3,4,5$, and $6 \%$, respectively. However, the actual lactose concentrations measured using the HPLC-based reference method in the model skim milks were found to be $2.05,3.05,3.74,4.74$, and $5.80 \%$, respectively. Figure 3 shows the calibration equations obtained for lots 1 and 2. The slopes and intercepts were found to be 0.91 and -17.36 for lot 1 and 0.94 and -28.75 for lot 2 , respectively. The calibration equations were used to predict the lactose content of the raw milk samples. Table 5 provides the statistical parameters obtained during the comparison of the glucose meter method against the HPLC-based method. The average bias (mean difference) between the 2 methods was found to be -0.05 and $0.08 \%$ for the 2 lots of test strips. It was also observed that the lot 1 strips underestimated lactose content, producing a negative bias. On the other hand, lot 2 overestimated lactose content, producing a positive bias. The
CV calculated between the 2 lots of test strips were between 1.4 and $3.3 \%$ with an average CV of $2.2 \%$. Kwak and Jeon (1988) reported similar findings during comparison of HPLC and enzymatic methods. In their work, the HPLC method and enzymatic method produced CV of 1.02 and $2.75 \%$, respectively, and the mean difference between the 2 methods was $0.15 \%$. Kleyn (1985) also reported a CV between 2.89 and $5.66 \%$ for the enzymatic method during measurement of the lactose content of milk samples. However, Lynch et al. (2007) reported the lowest repeatability relative standard deviation of $0.29 \%$ for the enzymatic method when they used modifications to improve the original method.

Based on the findings in this work and from our experience with the proposed blood glucose meter method, the following protocol is recommended to measure lactose in milk.

1. Prepare calibration samples that contain $3.5 \%$ protein and varying concentrations of lactose $(2$, $3,4,5$, and $6 \%$ ) using milk protein concentrate 85, deproteinized whey powder, and distilled water.

2. For both calibration and milk samples, dilute $0.25 \mathrm{~mL}$ of sample with $5 \mathrm{~mL}$ of distilled water in a test tube and mix thoroughly. Add $0.1 \mathrm{~mL}$ of lactase enzyme (approximately 270 yeast lactose units) and incubate at $40^{\circ} \mathrm{C}$ for $10 \mathrm{~min}$.

3. Use a suitable blood glucose meter (ReliOn Ultima or any other compatible blood glucose meter) and corresponding test strips. A complete

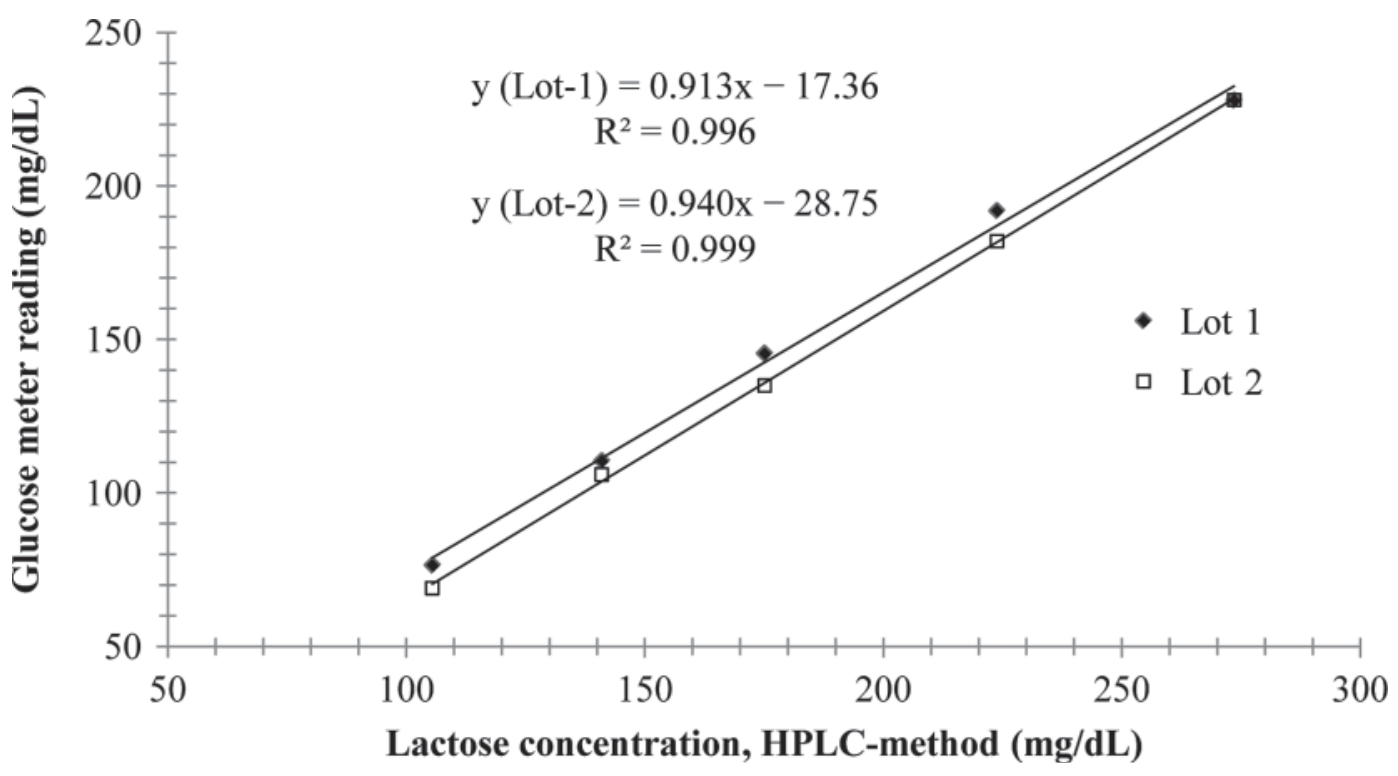

Figure 3. Calibration curves for lactose determination in model skim milk samples using blood glucose meter method. 
Table 5. Determination of lactose content in milk samples

\begin{tabular}{|c|c|c|c|c|c|c|c|c|}
\hline \multirow{3}{*}{$\begin{array}{l}\text { Sample } \\
\text { No. }\end{array}$} & \multicolumn{3}{|c|}{ Lactose concentration (\%) } & & & & & \\
\hline & \multirow{2}{*}{$\begin{array}{l}\text { HPLC } \\
\text { method }\end{array}$} & \multicolumn{2}{|c|}{ Glucose meter method } & \multicolumn{2}{|c|}{ Bias } & \multicolumn{2}{|c|}{$\mathrm{D}^{1}(\%)$} & \multirow[b]{2}{*}{$\% \mathrm{CV}$} \\
\hline & & Lot 1 & Lot 2 & Lot 1 & Lot 2 & Lot 1 & Lot 2 & \\
\hline 1 & 4.46 & 4.56 & 4.46 & -0.10 & 0.00 & 2.24 & 0.00 & 1.57 \\
\hline 2 & 4.51 & 4.66 & 4.45 & -0.15 & 0.06 & 3.33 & 1.33 & 3.26 \\
\hline 3 & 4.33 & 4.57 & 4.37 & -0.24 & -0.04 & 5.54 & 0.92 & 3.16 \\
\hline 4 & 4.58 & 4.59 & 4.50 & -0.01 & 0.08 & 0.22 & 1.75 & 1.40 \\
\hline 5 & 4.38 & 4.39 & 4.22 & -0.01 & 0.16 & 0.23 & 3.65 & 2.79 \\
\hline 6 & 4.53 & 4.54 & 4.42 & -0.01 & 0.11 & 0.22 & 2.43 & 1.89 \\
\hline 7 & 4.47 & 4.45 & 4.34 & 0.02 & 0.13 & 0.45 & 2.91 & 1.77 \\
\hline 8 & 4.34 & 4.35 & 4.23 & -0.01 & 0.11 & 0.23 & 2.53 & 1.98 \\
\hline 9 & 4.59 & 4.65 & 4.48 & -0.06 & 0.11 & 1.31 & 2.40 & 2.63 \\
\hline 10 & 4.09 & 4.06 & 3.97 & 0.03 & 0.12 & 0.73 & 2.93 & 1.59 \\
\hline Average bias & & & & -0.05 & 0.08 & & & \\
\hline
\end{tabular}

${ }^{1}$ Mean percentage difference.

${ }^{2}$ Calculated between lot 1 and lot 2 of test strips (2 lots are treated as replicates).

list of compatible meters can be found in Schleis (2007). Detailed instructions on the operation and troubleshooting are available with the blood glucose meter.

4. Develop a linear lot-specific calibration model from the actual lactose concentrations and the blood glucose meter readings of the calibration set. From slope and intercept of linear calibration model, and dilution factor (0.0467) calculate lactose concentration in the sample using equation 1:

$$
\text { Lactose }(\%)=\frac{\text { Glucose meter reading }+ \text { Intercept }}{\text { Slope } \times 0.0467 \times 1,000} .[1]
$$

To summarize the advantages of the blood glucose meter method, the proposed method is simple to perform and does not involve extensive sample preparation. Moreover, the glucose meter method does not require any special instruments, such as a spectrophotometer, or the handling of hazardous chemicals. The method can be performed in 10 to $12 \mathrm{~min}$.

\section{CONCLUSIONS}

This paper evaluated the potential of a method based on a blood glucose meter for rapid determination of lactose in milk. The standardized procedure is simple and rapid and requires minimal training to perform. It can be a useful method for the dairy industry for rapid determination of lactose in milk and milk products. The low cost of the test for lactose (supplies to conduct a single test is $\$ 0.40$ for the test strip and a one-time cost of approximately $\$ 10$ for the glucose meter) makes it feasible for routine analysis in the dairy industry. This method could be extended to other dairy products, such as whey or cheese, with minor modifications in the method.

\section{ACKNOWLEDGMENTS}

We thank Midwest Dairy Association (St. Paul, MN), and Dairy Management Inc. (Rosemont, IL) as administered by Dairy Research Institute for their financial support. We are also thankful to Ruplal Choudhary (Southern Illinois University, Carbondale) and Kartik Shah (South Dakota State University, Brookings) for their help in the HPLC analysis of samples.

\section{REFERENCES}

Abboud, M. M., I. H. Aljundi, K. M. Khleifat, and S. Dmour. 2010. Biodegradation kinetics and modeling of whey lactose by bacterial hemoglobin VHb-expressing Escherichia coli strain. Biochem. Eng. J. $48: 166-172$

AOAC. 2000. Official Methods of Analysis. 17th ed. AOAC International, Gaithersburg, MD

Bergenstal, R., J. Pearson, G. S. Cembrowski, D. Bina, J. Davidson, and S. List. 2000. Identifying variables associated with inaccurate self-monitoring of blood glucose: Proposed guidelines to improve accuracy. Diabetes Educ. 26:981-989.

Briggs, A. L., and S. Cornell. 2004. Self-monitoring blood glucose (SMBG): Now and the future. J. Pharm. Pract. 17:29-38.

Cohen, M., E. Boyle, C. Delaney, and J. Shaw. 2006. A comparison of blood glucose meters in Australia. Diabetes Res. Clin. Pract. $71: 113-118$.

Conzuelo, F., M. Gamella, S. Campuzano, M. A. Ruiz, A. J. Reviejo, and J. M. Pingarr. 2010. An integrated amperometric biosensor for the determination of lactose in milk and dairy products. J. Agric. Food Chem. 58:7141-7148.

Cuartas-Uribe, B., M. I. Alcaina-Miranda, E. Soriano-Costa, J. A. Mendoza-Roca, M. I. Iborra-Clar, and J. Lora-García. 2009. A study of the separation of lactose from whey ultrafiltration permeate using nanofiltration. Desalination 241:244-255.

Essig, A. M., and D. H. Kleyn. 1983. Determination of lactose in milk: Comparison of methods. J. Assoc. Off. Anal. Chem. 66:1514-1516. 
Holsinger, V. H. 1997. Physical and chemical properties of lactose. Pages 1-38 in Advanced Dairy Chemistry - 3: Lactose, Water, Salts, and Vitamins. P. F. Fox, ed. Chapman \& Hill, New York, NY.

Hones, J., P. Muller, and N. Surridge. 2008. The technology behind glucose meters: Test strips. Diabetes Technol. Ther. 10:S10-S26.

Iwasaki, T., K. Abukawa, S. Sasaki, A. Kajiro, T. Ota, A. Hosono, S. Chiyokawa, and K. Suyama. 2008. A new method for determination of lactose content in cow's milk: Comparison with the Lane \& Eynon method. Milchwissenschaft 63:303-305.

Jeon, I. J., S. J. Galitzer, and K. J. Hennessy. 1984. Rapid determination of lactose and its hydrolyzates in whey and whey permeate by high performance liquid chromatography. J. Dairy Sci. 67:884-887.

Kimberly, M. M., H. W. Vesper, S. P. Caudill, S. F. Ethridge, E. Archibold, K. H. Porter, and G. L. Myers. 2006. Variability among five over-the-counter blood glucose monitors. Clin. Chim. Acta 364:292-297.

Kleyn, D. H. 1985. Determination of lactose by an enzymatic method. J. Dairy Sci. 68:2791-2798.

Kleyn, D. H., and J. R. Trout. 1984. Enzymatic-ultraviolet method for measuring lactose in milk: Collaborative study. J. Assoc. Off. Anal. Chem. 67:637-640.

Kosinski, E. D. 1981. The indirect determination of lactose using a glucose analyzer with particular reference to solutions containing low levels of lactose in high levels of glucose and galactose. J. Dairy Technol. 34:28-31.

Kristensen, G. B. B., N. G. Christensen, G. Thue, and S. Sandberg. 2005. Between-lot variation in external quality assessment of glucose: Clinical importance and effect on participant performance evaluation. Clin. Chem. 51:1632-1636.
Kwak, H. S., and I. J. Jeon. 1988. Comparison of high performance liquid chromatography and enzymatic method for the measurement of lactose in milk. J. Food Sci. 53:975-976.

Lukacheva, L. V., A. A. Zakemovskaya, E. E. Karyakina, I. N. Zorov, A. P. Sinitsyn, M. V. Sukhacheva, A. I. Netrusov, and A. A. Karyakin. 2007. Determination of glucose and lactose in food products with the use of biosensors based on Berlin blue. J. Anal. Chem. 62:388-393.

Lynch, J. M., D. M. Barbano, and J. R. Fleming. 2007. Determination of the lactose content of fluid milk by spectrophotometric enzymatic analysis using weight additions and path length adjustment: Collaborative study. J. AOAC Int. 90:196-216.

Marrakchi, M., S. V. Dzyadevych, F. Lagarde, C. Martelet, and N. Jaffrezic-Renault. 2008. Conductometric biosensor based on glucose oxidase and beta-galactosidase for specific lactose determination in milk. Mater. Sci. Eng. C 28:872-875.

Morrissey, P. A. 1985. Lactose: Chemical and physicochemical properties. Pages 1-34 in Developments in Dairy Chemistry - 3. P. F. Fox, ed. Elsevier Applied Science Publishers, New York, NY.

Schleis, T. G. 2007. Interference of maltose, icodextrin, galactose, or xylose with some blood glucose monitoring systems. Pharmacotherapy 27:1313-1321.

Upreti, P., L. L. McKay, and L. E. Metzger. 2006. Influence of calcium and phosphorus, lactose, and salt-to-moisture ratio on cheddar cheese quality: Changes in residual sugars and water-soluble organic acids during ripening. J. Dairy Sci. 89:429-443.

West, L. G., and M. A. Llorente. 1981. High-performance liquid-chromatographic determination of lactose in milk. J. Assoc. Off. Anal. Chem. 64:805-807. 